\title{
How to Increase Motivation for Physical Activity among Youth
}

\author{
Izedin Mehmeti', Besim Halilaj² \\ 'Secondary School of Economics"Hasan Prishtina", Mitrovica, Kosovo, University of Prishtina, Faculty of Sport and Physical Education, Prishtina, Kosovo
}

\begin{abstract}
The primary aim of the present study was to explore motivational profiles for physical activity (PA) in current students of secondary schools. The participants of the study were $(N=526$; males $=267$ and females $=259), 8^{\text {th }}$ grade, and $9^{\text {th }}$ grade students from the four secondary schools in the central and northern part of Kosovo. Data were collected through focus group discussions for students, during the month of May and June 2014/2015 school year, in order to gather qualitative data regarding students' perceptions of motivation and participation in Physical Education (PE) and extracurricular PA activities. Based on study findings Kosovo schools are not creating supportive and attractive school environment for children and adolescents in doing (PA) and sports in daily basis. Many schools (PE Teachers) make a mistake requiring every child to became an athlete, by suppressing child motivation and enjoyment for sport and creative physical activities. PE and sports module school based should offer the opportunities for different physical activities that people can do for a life time. PE and sports curricula should be focused on giving the opportunity to every child to excel their own skill level, and integrate teaching strategies for "maximum movement for maximum kids".
\end{abstract}

Key words: motivation, participation, barriers, Physical Education (PE), Physical Activity (PA)

\section{Introduction}

Increasing the youngsters motivation for Physical Activities (PA) and recreation (indoor and/or outdoor activities) is not an easy task. Physical Education (PE) Teachers and sport practicioners have to work closely and find a successful qualitative strategy, and programs according to the children and/ or youth needs and abilities. Play is an activity that young children and teenagers do every day. The research shows that play is very important tool to youngster's learning. What can we do to help youngsters to get the most learning from their play on daily basis, especially during the time they are at school? The rate of change in the world demands that we re-imagine and restructure the foundational learning relationship among students, teachers, and knowledge. The main goal of this research study was to discover what Kosovo schools (PE teachers) are doing in order to prepare students for an evolving future. However, as we grow as a human race we slowly gain the capability and comfort zone to raise the standard and we already have the tools necessary to change the system so that it is directed towards all individuals. This remains the problem however, how do we change the whole system because it obviously isn't working at the moment as a lot of kosovans, unfortunately literally „hate" their schools (PE too), .Acording to the study findings, Kosovo youngsters showed the tendency of decreased motivation for doing PE and sports. Health and wellbeing is highly ranked in list of basic human rights, to be a good defender of children and youth rights; there is a need for a jointly efforts in raising awareness for children and youth health. In today hectic lifestyle, keeping fit and exercising seems to be the last thing on young generation's priority list. What they don't understand exactly is that health doesn't mean only the absence of the chronic disease, it means physical, mental and social health balance. It has been well documented that engagement in PA decreases during adolescence (Currie, Gabhainn, \& Godeau, 2008; Dumith, Hallal, Reis, \& Kohl, 2011). During the adolescent developmental period,

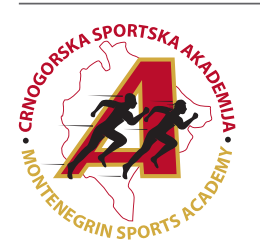

Correspondence:

I. Mehmeti

Secondary School of Economics"HasanPrishtina", Rr.:"UÇK", nr 4, 1000, Mitrovica, Kosovo

E-mail: kosovaari@yahoo.com 
there are a multitude of psychological, physical and social factors which may influence the decrease in PA patterns (Sallis, Prochaska, \& Taylor, 2000). The development of motivation is a process which takes time(Deci \& Ryan, 2000).

In a recent literature review, Bassett et al. (2013) found that physical education contributes to children achieving an average of 23 minutes of vigorous-or moderate-intensity physical activity daily. However, the time spent in vigorous-or moderate-intensity PA could be increased by 6 minutes if the physical education curriculum were to incorporate a standardized curriculum such as SPARK (Bassett et al., 2013). Thus, it is possible for physical education to contribute to youth meeting at least half (30 minutes) of their daily requirement for vigorousor moderate-intensity physical activity. To help children grow holistically, however, physical education needs to achieve other learning goals when children are active. To this end, physical education programs must possess the quality characteristics specified by National Association of Sport and Physical Education-NASPE (2007; 2009a; 2009b).

Designing and implementing a PE program with these characteristics in mind should ensure that the time and curricular materials of the program enable students to achieve the goals of becoming knowledgeable exercisers and skillful movers who value and adopt a physically active and healthy lifestyle. Because PE is part of the curriculum in schools, its quality should be judged only by whether and to what extent children have learned and benefited from it. In a landmark document on learning goals, Moving into the Future: National Standards for Physical Education (NASPE, 2004) proposes six student learning standards specifying both conceptual and behavioral characteristics that a physically educated person must possess and display.

These characteristics encompass knowledge, skill, behavior, and confidence critical to the development and maintenance of health and the enjoyment of a physically active and healthful lifestyle. A high-quality PE program can help youth meet the guideline of at least 60 minutes of vigorous-or moderate-intensity physical activity per day. This increase in PA should be balanced with appropriate attention to skill development and to national education standards for quality PE. What about Kosovo national standards for quality PE!? In spite of the fact that according to the Ministry of Education Science and Technolgy (MEST) people in charge, they are working hardly on establishing, national standards for PE, the secondary school students, pre service and in service PE teachers in Kosovo have no clue about these standards!?

The purpose of this study is to examine two research questions:1) What are students' perceptions of motivation and participation in PE and extracurricular PA and sport activities? and2) What are the motivational triggers for PA and recreational activities?

\section{Methods}

The participants of the study were $(\mathrm{N}=526$; males $=267$ females $=259) 8^{\text {th }}$ grade and $9^{\text {th }}$ grade students from the four secondary schools in the central and northern part of Kosovo. The average age of the participants was $14.28(\mathrm{SD}=1.47)$. Students carried out motivational and participation of self reported questionnaires to gather quantitative data regarding students' perceptions of motivation and participation in PE. Sport Anxiety Test (SCAT)(Martens et al., 1990) is a 15-item self-report measure of sport competition anxiety level for stu- dent participation in physical activity (PA), $\mathrm{PE}$, answering the stem question (before I compete, I worry about not performing well...): When I compete, I worry about making mistakes), ( before I compete, I get a queasy feeling in my stomach), (just before competing, I notice my heart beats faster than usuall), (before I compete I am nervous), (Team sports are moreexiting than individual sports). Each item uses a 5-point Likert scale ranging from $1=$ strongly disagree to $5=$ strongly agree. Also, the participants were asked to state the number of days engaging in physical activity during a typical week and how important/useful/interesting exercise is for them, rated in a 5 -point Likert scale ranging from $1=$ nothing at all to $5=$ very much. Self-report measure of motives for participation in PA. Students showing lack of motivation for doing PA/PE activities were members of the focus group discussions moderated by the researcher. Each item uses a 5-point Likert scale ranging from $1=$ strongly disagree to $5=$ strongly agree. Data were also collected through focus group discussions for less motivated students for being engaged in PA and PE activities, during the month of May and June 2014/2015 school year, in order to gather qualitative data regarding students' perceptions of motivation and participation in PE and extracurricular Physical and sport activities. Participants were also asked to state their motivation for doing PE activities, what are their preferences about sports and recreational activities? What is their oppinion about the PE teacher? What is the number of days engaging in physical activities during a typical week and how important/useful/interesting exercise is for them?,rated in a 5-point Likert scale ranging from $1=$ nothing at all to $5=$ very much.

\section{Data collection}

Questionnaire items were designed by the author to reflect the research questions. Items sought information on student perceptions about their motivation for voluntary engagement in $\mathrm{PE}, \mathrm{PE}$ teachers' role in their motivation for engagement in school based PE/Sport activites. Possible opportunities to transform students motivation for physical activity into motivation. Additional items included information related to curricular contents youngsters prefer to learn in school based PE. Focus group interview questions were modelled after the questionnaire so that the same topics were probed and answered in greater detail. Students were informed of the purpose of the study and the confidential treatment of the data. The study was explained by the researcher at the beginning of each class and questionnaires were distributed to every student who participated in the study. In general, questionnaires were completed in about 15-20 minutes.

\section{Data analysis}

Questionnaire data were analyzed using three computerized programs. Quantitative data was analyzed using SPSS 21, a predictive analytic applications software, to provide mean and standard deviations derived from the five Likert-scaled questions. Excel was used to organize data from the open-ended questions.

\section{Results}

In this study results bring attention to the daily reality in Kosovo public schools over the past 20 years. In the newborn country (Kosovo), unfortunately, based on study participants; there has been a gradual but overall dramatic decline in teenager's freedom to play with other peers, without adult 
direction. Over this same period, there has been a gradual but overall dramatic increase in anxiety, depression, feelings of helplessness, and narcissism in children and adolescents due to traditional way of Teaching PE, not applying student centered methodologies and strategies of Teaching PE school based.

Study findings show that: Children and adolescents in the Republic of Kosovo schools cannot become more physically active and fit if they don't have a wide range of accessible, safe and affordable opportunities to be active. These study results are in accordance with similar study research assessing secondary school students motivation for PE/PA activities, Mehmeti (2015) adolescents are not motivated enough by PE teachersby not reflecting positively as a good role-model for them. The term role model is defined as a person whose behavior, example, or success is or can be emulated by others, especially younger people (Random House Dictionary). Basketball was moreanxiety-arousing than other team sports in school. Some of the youngsters experienced extremely high levels of stress before competitive activities, regardless of the sport. The majority of study respondents (89\%), declared they are not intrinsically motivated to be engaged regularly in PE school based activities. Also, (91\%) of them declared that they don't know that there is any sport club doing practices and representing school, at municipality level or at regional and state level. Negative peer pressure seems to be one of the larger barrier mentioned by the students when it comes to the students engagement in school based PE activities, seventy-eight percent of students declared that:.. if We have no school gym, its not fair to be forced for doing PE regularly, on weekly basis. $\mathrm{PE}$ teachers are not doing their best to teach students basics of $\mathrm{PE}$ and sports according to study participants, $68 \%$ of students declared that their PE teacher was never engaged during the PE classes with students.

Previous research on children and adolescents' self-reported barriers to participation in $\mathrm{PE}$ and physical activity has reported changing attitudes to activity and $\mathrm{PE}$, adolescents' decision making favoring more sedentary activities. Similar to our study findings, $(71.8 \%)$ percent (219), stated that their PE teachers, focus on too many traditional and team sports, like football, basketball, and volleyball. By analyzing a student's response to a series of statements about how she/he feels in a competitive situation it is possible to determine their level of anxiety. A test that provides such functionality is the Sport Anxiety Test (SCAT)(Martens et al., 1990).

Theoretically, the $21^{\text {st }}$ century schools are supposed to be also the places where students are able to express their opinions and be part of creating a healthy safe supportive climate in their schools. PE classes are the perfect setting for implementation of the theory into practice, PE curriculum content is not just physical activity, competitive sports, highly structured activities, lack of teacher support, it's a kind of puzzle' pieces.

\section{Discussion}

It is interesting to think why play is declining in most countries, not only in Kosovo.It is hard to understand that in Kosovo where kids grew up 20-30 years ago, where a school age childrenwere playing outdoor, street ball, football, volleyball and lots of plays, but today, we are almost not seeing youngsters playing outdoors.

Focus group transcript:

Tony (pseudonym): I am a child, 14 nearly 15 in secondary school, year 8 (Bolognia Education System). A lot of the time, even right now I feel physically sick when I think about school and homework. I talked to my friends and they said they feel that way too. I don't understand how they(Ministry of Education Science and Technology (MEST), and Teachers) think this is a good educational system for children, children are sick with worry about school. But, we need an educational system when children look forward to school instead of thinkingthat the only good thing is your friendwhich is how I feel. This is all coming from a child who is forteenyears old and is within the Kosovo's educational system right now:...One last thing we have much less "creative" lessons during PE classes than for e.g.Physics and English language etc.

Alex (pseudonym), 32 years of experience in teaching Physical Education. Yes, the students motivation in PE has decreased a loot nowdays: If I compare it to my first year of teaching, it's white and black. I think we PE teachers have to work harder, finding the ways by using creativity and be more open minded teachers in order to increase student motivation in school based PE classes...

School aged children and youth are evaluated these days mainly on the basis of the student's test performance. Nowadays, students are increasingly encouraged or required to take teacher (adults)-directed lessons (sports) even out of school, rather than to play unconventional games freely. What matters in today's educational world is performance, $(88 \%)$ of the secondary school studentsdeclared that PE teachers all what they do is assessing students physical fitnees, time to time, and thats all ( $88 \%$ of respodents) These results than can be scored and compared accross students, across schools, municipalities, and at the state level, and even accross nations to see who is the best? This shows us that PE teachers are mainly focused on sport performance rather than strategies for increasing students motivation for doing physical activities in their daily routine.

However, this study provides further insights, demonstrating that there is a long list of different barriers thatteachers may encounter when providing PE in Kosovo secondary schools. Participation barriers including those imposed by the students themselves; lack of affordable school facilities, no gym sports, unsafety school yards, lack of sport equipment and requisites, large class sizes, traditional teaching methodologies (teacher centered teaching, $\mathrm{PE} /$ sports not priorities in the school (PE ranked on the bottom of list of priorities), focus on too many traditional sports, competitive team sports, repetitive/not attractive learning topics, negative peer pressure, strict $\mathrm{PE}$ teacher/instructional strategies, past negative experiences of students during PE classes.

This study results are in same line with research of McKenzie (2007), the study has made clear that certified PE specialists can provide more and longer opportunities for students to meet physical activity guidelines compared with classroom teachers trained to teach PE. Getting younger adolescents active on a daily basis is crucial to their overall health and development. PE class should not serve to be a "break" from academics. Play and physical activity is learning and very important learning at that. The benefits are well researched and documented as to the importance of youngsters getting daily physical activity. Our schools are a major let down and we need people involved who realize the importance of living a healthy lifestyle on a daily basis. School should be the place where students learn balanced way of living, and develop good habits for healthy lifestyle in the future. School should be the place where students find 
healthy, safe, supportive climate, in case we want to fulfil the goal of increasing stduents' motivation for physical activity on daily basis. Republic of Kosovo schools are not creating supportive and attractive school environment for children and adolescents in doing PA and sports in daily basis. Many schools (PE Teachers) make a mistake requiring every child to became an athlete, by suppressing child motivation and enjoyment for sport and creative physical activities. PE Teachers can help the students they care about healthier life by serving as a good role model by making physical activity (PE classes), and extracurricular activities (intramural sports) and healthy eating their priorities of daily routine. Enhancing youngsters physical activities and playing activities, we tend to enhance students possibilities of fulfilling the goals and objectives of secondary school curriculum. By increasing youth engagement and enhancement of their playing time, but this leads directly to overall advancement of students' development.

Definitelly, there is an urgent need for PE teachers to apply a variety of activities to do it with children and kids if we really want to increase their motivation for engagement in PE classes, regular PA is important factor for students health. Some of the main findings of this study wherethere is a need for PE teachers to design and implement programs to create a learning environment that emphesizes skill development, personal and team success and having fun, and reduce performance-destroying anxiety and fear of failure.

\section{Acknowledgements}

There are no acknowledgements.

\section{Conflict of Interest}

The authors declare there are no conflict of interest.

Received: 07 September 2017| Accepted: 13 November 2017

\section{References}

Barker, H.B. (2013). Improving high school students' participation in physical education. Unpublished MA thesis. Sierra Nevada College.
Bassett, D.R., Fitzhugh, E.C, Heath, G.W., Erwin, P.C., Frederick, G.M., Wolff, D.L., Welch, W.A. \& Stout, A.B. (2013). Estimated energy expenditures for school-based policies and active living. American Journal of Preventive Medicine, 44(2), 108-113.

Currie, C., Gabhainn, S.N., Godeau, E., Roberts, C., Smith, R., Currie, D., \& Barnekow, V. (2008). Inequalities in young people's health. HBSC international report from the 2005/2006 survey. Copenhagen, Denmark: WHO Regional Office for Europe.

Couturier, L.E., Chepko, S., \& Coughlin, M.A. (2005). Student voices-What middle and high school students have to say about physical education. Physical Educator, 62(4), 170-177.

Deci, E.L., \& Ryan, R.M. (2000). Self-determination theory and the facilitation of intrinsic motivation, social development, and well-being. American Psychologist, 55, 68-78.

Dumith, S.C., Hallal, P.C., Reis, R.S., \& Kohl, H.W. (2011). Worldwide prevalence of physical inactivity and its association with human development index in 76 countries. Preventive Medicine, 53(1-2), 24-28.

Le Masurier, G., \& Corbin, C.B. (2006). Top 10 reasons for quality physical education. Journal of Physical Education, Recreation \& Dance, 77(6), 44-53.

McKenzie, T.L. (2007). The preparation of physical educators: a public health perspective. Quest, 59, 346-357.

Mehmeti, I. (2015). Motivational level and participation barriers in school physical education among adolescents. Paper presented at the $12^{\text {th }}$ International Scientific Conference on Transformation Processes in Sport, Podgorica, Montenegro. April 2015, from http://www.sportmont.ucg. ac.me/conference2015.

National Association of Sport and Physical Education-NASPE (2004). Moving into the future: National standards for physical education. St. Louis, MO: Mosby.

National Association of Sport and Physical Education-NASPE (2007). Position statement: What constitutes a highly qualified physical education teacher Reston, VA: AAHPERD.

National Association of Sport and Physical Education-NASPE (2009a). School physical education program checklist-How does your program rate. Reston, VA: AAHPERD.

National Association of Sport and Physical Education-NASPE (2009b). NASPE resource brief: Quality physical education. Reston, VA: AAHPERD.

Sallis, J.F., Prochaska, J.J., \& Taylor, W.C. (2000). A review of correlates of physical activity of children and adolescents. Medicine and Science in Sports and Exercise, 32, 963-975.

Telama, R., Yang, X., Viikari, J., Välimäki, I., Wanne, O., \& Raitakari, O. (2005). Physical activity from childhood to adulthood: A 21-year tracking study. Americal Journal of Preventive Medicine, 3, 267-273. 